\title{
Impact of postoperative complications on long-term survival of gastric cancer patients: results from a high-volume institution in China
}

Hua-Yang Pang

Sichuan University West China Hospital

Hui Wang

Sichuan University West China Hospital

Lin-Yong Zhao

Sichuan University West China Hospital

Xiao-Long Chen

Sichuan University West China Hospital

Kai Liu

Sichuan University West China Hospital

Wei-Han Zhang

Sichuan University West China Hospital

Kun Yang

Sichuan University West China Hospital

Xin-Zu Chen

Sichuan University West China Hospital

Jian-Kun Hu ( $\nabla$ hujkwch@126.com )

Sichuan University West China Hospital https://orcid.org/0000-0001-6905-3934

\section{Research}

Keywords: Gastric cancer, Postoperative complications, Overall survival

Posted Date: April 23rd, 2020

DOI: https://doi.org/10.21203/rs.3.rs-23898/v1

License: (c) (i) This work is licensed under a Creative Commons Attribution 4.0 International License.

Read Full License 


\section{Abstract}

\section{Background}

This study was aimed to evaluate the impact of postoperative complications (POCs) on long-term survival for gastric cancer (GC) patients with curative resection.

Methods

From January 2009 to December 2014, a total of 1667 GC patients with curative gastrectomy were analyzed. Patients with any complications Clavien-Dindo (CD) grade II or higher were divided into complication group. Independent risk factors for the development of POCs and the relationship between POCs and long-term survival (excluding death within 90 days after surgery) were analyzed.

Results

Overall POCs $C D \geq 2$ were diagnosed in 285 (17.10\%) patients including infectious complications (ICs) in 231 (13.9\%) and noninfectious complications (NICs) in 78 (4.68\%) patients. Age $\geq 65(P=0.003)$, presence of comorbidity $(P=0.019)$, extensive lymphadenectomy $(P=0.027)$ and perioperative blood transfusion $(P=0.040)$ were independent risk factors of POCs. Multivariate analysis identified that presence of POCs $(P<0.001)$ was an independent prognostic factor and further analysis by complication type demonstrated that the deteriorated overall survival was mainly caused by ICs $(P=0.007)$ rather than NICs $(P=0.075)$, moreover, among all complications, pulmonary infection $(P<0.001)$ was the only significant prognostic factor.

Conclusion

POCs may be an independent prognostic factor for long-term survival of GC patients and the risk is mainly driven by ICs, particular pulmonary infection.

\section{Introduction}

Gastric cancer (GC) is the fifth most frequently diagnosed cancer and the third leading cause of cancer death worldwide [1]. Gastrectomy with curative resection is the most effective treatment strategy which provides the chance to dramatically extend the long-term survival of gastric cancer patients. However, surgery for gastric cancer still remains technically demanding and the following postoperative complications (POCs) have been reported to be with a wide range of incidence of 7-46\% [2-5].

Recent studies have shown that POCs increase the length of hospital stay and early mortality $[6,7]$. Moreover, POCs decrease the overall survival (OS) and disease free survival (DFS) in several types of cancer like lung, breast and colon [8-10], and this effect might is mainly strengthened by infectious complications (ICs) not noninfectious complications (NICs) [11-13]. Therefore, the prevention and treatment of POCs may play a crucial role to improve the surgical outcomes of cancer patients. 
Currently, in gastric cancer, although increasing numbers of studies have suggested that presence of POCs is adversely correlated with long-term survival [14-18], several studies reported from both eastern and western countries have negative findings [19-22]. What's more, which kind of specific complication in gastric cancer would have a crucial effect on the long-term survival has only been discussed in few studies [21, 23] and remains far from resolved.

The aim of this study was to explore the relationship between POCs and the long-term survival,and to identify factors associated with the development of POCs.

\section{Methods}

\section{Patients and ethical issues}

A total of 2210 consecutive patients with gastric adenocarcinoma who underwent gastrectomy were selected from the database of Surgical Gastric Cancer Patient Registry in West China Hospital (WCHSGCPR) from January 2009 to December 2014, with registration number WCH-SGCPR 2018-03 and the establishment of this database was approved by the Research Ethics Committee of West China Hospital. The inclusion criteria included: 1) histologically proven gastric adenocarcinomas; 2 ) with radical surgical resection (R0); 3) without preoperative therapy; 4) no distant metastasis. The exclusion criteria of our study included: 1) with other synchronous or metachronous (within 5 years) cancers; 2 ) remnant gastric cancer; 3) with harvested number of lymph node less than 15;4) with emergency treatment. Additionally, patients died within 90 days (all the death was directly associated with serious intra- or post-operative complications) after surgery were also excluded to avoid exaggerating the effect of POC on long-term survival. Finally, 1667 patients who underwent gastrectomy with potentially curative resection were enrolled into this study, as shown in Fig. 1.

Potentially curative resection is regarded as gastrectomy with R0 resection combined with adequate lymphadenectomy. The surgery was performed by experienced surgeons according to the Japanese gastric cancer treatment guidelines [24]. The resected specimens were pathologically classified according to the JGCA classification [25], and staged with the updated AJCC 8th TNM system [26].

\section{Assessment of postoperative complications}

In the present study, the Common Terminology Criteria for Adverse Events (CTCAE) version 4.0 [27], which is enough exhaustive in terms of postoperative morbidities, was used to define complications, and any morbidity classified as Clavien-Dindo (CD) grade II or higher that developed during hospitalization or within 30 days after surgery was identified as a POC using Clavien-Dindo grade system [28,29]. However, grade I complications were not evaluated considering the potential description bias in the patient records. If a patient suffered more than one POC, the highest-ranked complication was used for grade analysis.

All complications were categorized as ICs or NICs. ICs included pulmonary infection, abdominal abscess, anastomotic leakage, wound infection, pancreatic leakage, pancreatitis, intestinal leakage, cholecystitis, 
urinary system infection, appendicitis and bacteremia. NICs included gastroparesis, intestinal obstruction, intra-abdominal hemorrhage, pleural effusion, ascites, atelectasis, respiratory failure, heart failure, arrhythmia, deep venous thrombosis.

\section{Follow-up}

The follow-up was mainly performed by out-patient visit, meanwhile, routine telephone interviews were regarded as important supplementary methods. The last update of follow-up information was Jan 1 , 2019. In the 1667 patients, 168 of them lost contact during follow-up, the follow-up rate was $89.92 \%$ with the median follow-up time 78.05 (3.20-118.50) months. The main reasons for lost follow-up are because of the change of telephone number and address and refusal to attend to out-patient interview of our hospital.

\section{Statistical Analysis}

The analyses were all performed with software IBM SPSS Statistics version 23.0 (International Business Machines Corporation, Armonk, NY, USA). Statistical analysis was performed using descriptive statistics for demographic data. For group-wise comparisons, Student t test (normal distribution) or Mann-Whitney U test (nonparametric distributions) were used. To compare nominal data, the Chi-square test or the Fisher exact test was used. The subsequent multivariate logistic regression analysis was performed to detect independent risk factors of POCs. The Kaplan-Meier method and log-rank test were used to calculate survival rates and compare the survival rates respectively. Univariate and multivariate Cox proportional hazards regression models were used to analyze the hazard ratios for overall survival. $\mathrm{P}$ value less than 0.05 was considered to be statistically significant.

\section{Results}

\section{Description of entire study cohort population}

The characteristics of the entire study cohort was presented in Table 1. The mean age of this population was $57.96 \pm 11.27$ years old with $69.23 \%$ male patients and $26.63 \%$ of them had a different kinds of comorbidities. Among these patients, distal gastrectomy (59.87\%) was the main surgical procedure followed by total $(27.41 \%)$ and proximal $(12.72 \%)$ gastrectomy combined with D2/D2 + lymphadenectomy (95.98\%) which is routinely performed in our center. Additionally, $15.72 \%$ of this population received perioperative blood transfusion. Regarding to pathological features, the advanced gastric cancer took up to $79.12 \%$ of the entire population and nodal involvement was observed in $68.51 \%$ patients. Besides, nearly $50 \%$ patients received adjuvant chemotherapy.

The details of POCs of this population were shown in Table S1. A total of $285(17.10 \%)$ patients developed complications CD $\geq$ II (II: 241 [14.46\%]; III: 24[1.44\%]; IV: 20[1.20\%]) in this cohort. Further, 246 ICs were found at 231 (13.86\%) patients, of which pulmonary infection (184 patients; $11.04 \%$ ) was the most common adverse event followed by intra-abdominal abscess (26 patients; $1.56 \%$ ) and wound 
infection (11patients; $0.66 \%$ ). Meanwhile, 84 NICs were observed in 78 (4.68\%) patients including gastroparesis (30 patients; $1.80 \%$ ), intestinal obstruction (11patients; $0.72 \%$ ) and pleural effusion (9 patients; $0.54 \%)$.

\section{Predictors related to occurrence of POCs}

Relationships between the occurrence of POCs and clinicopathological parameters are shown in Table 2. In univariate analysis, age 65 or higher $(\mathrm{OR}=1.65 ; 95 \% \mathrm{Cl}$ : $1.26-2.17 ; \mathrm{P}<0.001)$, presence of comorbidities ( $\mathrm{OR}=1.62 ; 95 \% \mathrm{Cl}: 1.20-2.13 ; \mathrm{P}<0.001)$, extensive lymphadenectomy (OR: $3.29 ; 95 \% \mathrm{Cl}$ : $1.02-10.66 ; \mathrm{P}=0.038)$ and perioperative blood transfusion $(\mathrm{OR}=1.60 ; 95 \% \mathrm{Cl}: 1.16-2.21 ; \mathrm{P}=0.001)$ were associated with POCs, other factors like histopathological parameters showed no significant relation with POCs. Further multivariate analysis identified that age 65 or higher $(\mathrm{OR}=1.54 ; 95 \% \mathrm{Cl}: 1.16-2.04 ; \mathrm{P}=$ $0.003)$, presence of comorbidities $(\mathrm{OR}=1.42 ; 95 \% \mathrm{Cl}: 1.06-1.91 ; \mathrm{P}=0.019)$, extensive lymphadenectomy $(\mathrm{OR}=3.80 ; 95 \% \mathrm{Cl}: 1.16-12.41 ; \mathrm{P}=0.027)$ and perioperative blood transfusion $(\mathrm{OR}=1.43 ; 95 \% \mathrm{Cl}: 1.02-$ $2.01 ; \mathrm{P}=0.040$ ) were independent risk factors for development of POCs.

\section{Prognostic Significance of POCs on long-term survival}

As shown in Fig. 2a, patients with POCs had a significant worse OS compared with those without (3-year OS rate $60.4 \%$ vs. $71.3 \%$; $\mathrm{P}<0.001)$. The overall survival curves stratified by pathological stage were shown in Fig. $2 b-d$. The curves were significantly separated in stage III cancers with $P<0.001$, however, no obvious difference was observed in stage I, II. Univariate and subsequent multivariable Cox regression analysis revealed that POCs $(\mathrm{HR}=1.47 ; 95 \% \mathrm{Cl}$ : 1.22-1.78; $\mathrm{P}<0.001)$ along with tumor size, tumor invasion depth, nodal involvement and adjuvant chemo-therapy were independent prognostic factors (Table 3).

\section{Relation between specific complications and long-term survival}

To clarify which kind of complications had a contribution on poor OS, we performed univariate and multivariate analysis using each complication with other parameters. In the univariate analysis, both ICs (3-year OS rate $60.5 \%$ vs. $71.2 \% ; \mathrm{P}=0.002$ ) and NICs (3-year OS rate $62.0 \%$ vs. $69.8 \% ; \mathrm{P}=0.045$ ) had an adverse influence on OS (Fig. 3; Table 3). However, multivariate analysis demonstrated that only ICs (HR, 1.34; 95\%Cl: 1.08-1.66; $P=0.007)$ rather than NICs $(H R, 1.34 ; 95 \% \mathrm{Cl}: 0.97-1.86 ; P=0.075)$ was independent prognostic factor for unfavorable OS.

Among all complications with events five or more, only pulmonary infection had a significant negative effect on OS (3-year OS rate $58.8 \%$ vs. $70.7 \%$; $P=0.004$ ) in the univariate analysis (Fig. 3; Table 4), and subsequent multivariate analysis identified that pulmonary infection was an independent prognostic factors (HR, 1.52; 95\% Cl: 1.20-1.91; $\mathrm{P}<0.001)$ (Table 4).

\section{Discussion}


Several previous studies have reported the relationship between POCs and long-term survival in gastric cancer, however, the results still remain controversial [11, 15-17, 20-23, 30-36]. Additionally, these studies failed to exclude patients who died in a short postoperative period. Of note, POCs increase the early mortality, which would overshadow the real influence of complications on long-term survival of cancer patients [37, 38]. In the present study, $1667 \mathrm{GC}$ patients with curative resection were analyzed and $17.10 \%$ of them occurred POCs C-D $\geq$ II (excluding deaths within 90 days after surgery). Older age, comorbidities, extensive lymph node dissection and perioperative blood transfusion were associated with a high incidence of POCs. With respect to the relationship of complication and survival, we revealed (1) that occurrence of POCs was indeed significantly associated with shortened long-term OS, (2) ICs were the mainly driver for poor survival instead of NICs, (3) among all complications, pulmonary infection in this study was the greatest risk factor for the decreased OS.

The influence of POCs, particularly ICs, on long-term survival has been described in several types of cancer [11-13].Recently, in a systematic review and meta-analysis about the effect of POCs on long-term survival in patients with curative gastrectomy, Wang et al. identified a $40 \%$ higher risk of death in patients with POCs and a much higher (86\%) mortality risk in patients with ICs compared with those without, respectively [39], which was in line with our results. Similarly, in lung cancer, a similar outcome reported by Andalib et al. have also demonstrated that major ICs were the main reason for worse long-term survival and NICs had a minor effect on this bad outcome, excluding early deaths [11].

With respect to the mechanism of presence of complications on poor survival, Accumulated evidences $[17,40,41]$ had indicated that the surgical stress, especially in major surgery, would induce body inflammatory response which could be enhanced and prolonged by POCs. It's also well established that postoperative inflammatory response has a contribution on host immunosuppression by mainly suppressing cell-mediated immunity [42,43], especially natural killer cells and cytotoxic T lymphocytes are compromised [43], which promotes the proliferation and metastasis of residual tumor cells. Furthermore, numerous researches have confirmed that ICs have a direct effect on cancer cell metastatic ability by activating bacterial antigen-mediated processes [44, 45]. Indeed, in our study, a remarkable difference in overall survival between patients stratified by presence of complication in p-Stage III is likely to reflect the quantity of residual tumor cells which would cause early recurrence.

Nevertheless, we have to admit that whether POCs have a direct cause-effect relationship on shortened survival is still not very clear. Alternatively, the pernicious effect of postoperative complications on longterm survival could be just a confounder, such as surgical technique, may be the reason for both occurrence of POCs and decreased long-term survival. What we can conclude in our study is that POCs have an influence on poor prognosis. Considering the curability of the POCs and its potential benefit on the long-term survival, it's worthy and crucial to prudently deal with POCs with active intervention and remediation. Meanwhile, for patients at risk of occurrence of POCs, such as those with older age, presence of comorbidities, extensive lymphadenectomy and perioperative blood transfusion, more attention should be paid to. 
The limitations of our study were its retrospective nature and presence of several confounding factors. And there was a lack of enough information about adjuvant chemotherapy, for example, the starting time of adjuvant chemotherapy among patients was not clear, which may have an effect on survival considering delayed chemotherapy is detrimental to prognosis. Another limitation was the inability to calculate DFS because its potential difficulty to get the precise recurrence time of these cancer patients in such a large population cohort. Despite these limitations, we believe that postoperative complications are an important prognostic factor.

In conclusion, postoperative complications after curative resection of gastric cancer are common and are associated with poor overall survival in gastric cancer patients. The risk is mainly driven by infectious complications (especially pulmonary infection) rather than noninfectious complications. Based on our findings, meticulous surgery is needed and prudent medical intervention in patients with complications is also compulsory to increase the long-term survival of gastric cancer patients.

\section{Abbreviations}

GC: gastric cancer

POC: postoperative complication

IC: infectious complication

NIC: noninfectious complication

CD: Clavien-Dindo

OS: overall survival

HR: hazard ratio

OR: odds ratio

Cl: confidence index

\section{Declarations}

\section{Ethics approval and consent to participate:}

This study was based on the information gathered from the database of the Surgical Gastric Cancer Patient Registry of West China Hospital (WCH-SGCPR) under registration number WCH-SGCPR 2018-03. The establishment of this database was approved by the Research Ethics Committee of West China Hospital. Informed consent individual patients were waived because of the retrospective nature of the analysis. 


\section{Consent for publication:}

Not applicable.

\section{Availability of data and materials:}

The datasets used and/or analyzed during the current study are available from the corresponding author on reasonable request.

\section{Competing interests:}

The authors declare that they have no competing interests.

Funding $\triangle$ This study was funded by (1) National High-tech R\&D Program (863 Program), No.2015AA020306; (2) 1.3 .5 project for disciplines of excellence, West China Hospital, Sichuan University, No. ZY2017304; (3) Post-Doctor Research Project, West China Hospital, Sichuan University (2018HXBH013) (4) Sichuan Province Cadre Health Care Research Project (No.2017-114)

\section{Authors' contribution:}

Jian-kun Hu, Hua-Yang Pang, Hui Wang make substantial contributions to conception and design for this study. Hua-Yang Pang, Hui Wang collect all the data. Hua-Yang Pang, Hui Wang, Lin-Yong Zhao, XiaoLong Chen, Kai Liu, Wei-Han Zhang analyze data, Hua-Yang Pang, Hui Wang, Xiao-long Chen draft the article. Kai Liu, Kun Yang, Xin-Zu Chen and Jian-kun Hu give critical revision for important intellectual content. Hua-Yang Pang and Hui Wang revising it critically for important intellectual content. Kun Yang, Xin-Zu Chen and Jian-kun Hu give final approval of the version to be published.

\section{Acknowledgment}

The authors thank the substantial work of Volunteer Team of Gastric Cancer Surgery (VOLTGA) West China Hospital, Sichuan University, China, for the establishment and updating of gastric cancer database.

\section{References}

1. Bray F, Ferlay J, Soerjomataram I et al. Global cancer statistics 2018: GLOBOCAN estimates of incidence and mortality worldwide for 36 cancers in 185 countries. CA Cancer J Clin. 2018;68(6):394424.

2. Zhao Y, Yu P, Hao Y et al. Comparison of outcomes for laparoscopically assisted and open radical distal gastrectomy with lymphadenectomy for advanced gastric cancer. Surgical endoscopy. 2011;25(9):2960-2966.

3. Sano T, Sasako M, Yamamoto $S$ et al. Gastric cancer surgery: morbidity and mortality results from a prospective randomized controlled trial comparing D2 and extended para-aortic lymphadenectomy- 
Japan Clinical Oncology Group study 9501. Journal of clinical oncology : official journal of the American Society of Clinical Oncology. 2004;22(14):2767-2773.

4. Cunningham D, Allum WH, Stenning SP et al. Perioperative chemotherapy versus surgery alone for resectable gastroesophageal cancer. The New England journal of medicine. 2006;355(1):11-20.

5. Cuschieri A, Fayers P, Fielding $\mathrm{J}$ et al. Postoperative morbidity and mortality after D1 and D2 resections for gastric cancer: preliminary results of the MRC randomised controlled surgical trial. The Surgical Cooperative Group. Lancet (London, England). 1996;347(9007):995-999.

6. Pucciarelli S, Zorzi M, Gennaro N et al. In-hospital mortality, 30-day readmission, and length of hospital stay after surgery for primary colorectal cancer: A national population-based study. European journal of surgical oncology : the journal of the European Society of Surgical Oncology and the British Association of Surgical Oncology. 2017;43(7):1312-1323.

7. Lang $\mathrm{H}$, Piso $\mathrm{P}$, Stukenborg $\mathrm{C}$ et al. Management and results of proximal anastomotic leaks in a series of 1114 total gastrectomies for gastric carcinoma. European journal of surgical oncology : the journal of the European Society of Surgical Oncology and the British Association of Surgical Oncology. 2000;26(2):168-171.

8. Aoyama T, Oba K, Honda M et al. Impact of postoperative complications on the colorectal cancer survival and recurrence: analyses of pooled individual patients' data from three large phase III randomized trials. Cancer medicine. 2017;6(7):1573-1580.

9. Nojiri T, Hamasaki T, Inoue M et al. Long-Term Impact of Postoperative Complications on Cancer Recurrence Following Lung Cancer Surgery. Annals of surgical oncology. 2017;24(4):1135-1142.

10. de Glas NA, Kiderlen M, Bastiaannet E et al. Postoperative complications and survival of elderly breast cancer patients: a FOCUS study analysis. Breast cancer research and treatment. 2013;138(2):561-569.

11. Andalib A, Ramana-Kumar AV, Bartlett $G$ et al. Influence of postoperative infectious complications on long-term survival of lung cancer patients: a population-based cohort study. Journal of thoracic oncology : official publication of the International Association for the Study of Lung Cancer. 2013;8(5):554-561.

12. Artinyan A, Orcutt ST, Anaya DA et al. Infectious postoperative complications decrease long-term survival in patients undergoing curative surgery for colorectal cancer: a study of 12,075 patients. Annals of surgery. 2015;261(3):497-505.

13. Yamashita K, Makino T, Miyata $\mathrm{H}$ et al. Postoperative Infectious Complications are Associated with Adverse Oncologic Outcomes in Esophageal Cancer Patients Undergoing Preoperative Chemotherapy. Annals of surgical oncology. 2016;23(6):2106-2114.

14. Hayashi T, Yoshikawa T, Aoyama T et al. Impact of infectious complications on gastric cancer recurrence. Gastric cancer : official journal of the International Gastric Cancer Association and the Japanese Gastric Cancer Association. 2015;18(2):368-374.

15. Li QG, Li P, Tang D et al. Impact of postoperative complications on long-term survival after radical resection for gastric cancer. World journal of gastroenterology. 2013;19(25):4060-4065. 
16. Fujiya K, Tokunaga M, Mori K et al. Long-Term Survival in Patients with Postoperative IntraAbdominal Infectious Complications After Curative Gastrectomy for Gastric Cancer: A Propensity Score Matching Analysis. Annals of surgical oncology. 2016;23(Suppl 5):809-816.

17. Kubota T, Hiki N, Sano T et al. Prognostic significance of complications after curative surgery for gastric cancer. Annals of surgical oncology. 2014;21(3):891-898.

18. Li Z, Bai B, Zhao Y et al. Severity of complications and long-term survival after laparoscopic total gastrectomy with D2 lymph node dissection for advanced gastric cancer: A propensity scorematched, case-control study. International journal of surgery (London, England). 2018;54(Pt A):62-69.

19. Kim SH, Son SY, Park YS et al. Risk Factors for Anastomotic Leakage: A Retrospective Cohort Study in a Single Gastric Surgical Unit. Journal of gastric cancer. 2015;15(3):167-175.

20. Saito T, Kurokawa Y, Miyazaki Y et al. Which is a more reliable indicator of survival after gastric cancer surgery: Postoperative complication occurrence or C-reactive protein elevation? J Surg Oncol. 2015;112(8):894-899.

21. Climent M, Hidalgo N, Vidal O et al. Postoperative complications do not impact on recurrence and survival after curative resection of gastric cancer. European journal of surgical oncology : the journal of the European Society of Surgical Oncology and the British Association of Surgical Oncology. 2016;42(1):132-139.

22. Watanabe M, Kinoshita T, Tokunaga $M$ et al. Complications and their correlation with prognosis in patients undergoing total gastrectomy with splenectomy for treatment of proximal advanced gastric cancer. European journal of surgical oncology : the journal of the European Society of Surgical Oncology and the British Association of Surgical Oncology. 2018;44(8):1181-1185.

23. Yuan P, Wu Z, Li Z et al. Impact of postoperative major complications on long-term survival after radical resection of gastric cancer. BMC cancer. 2019;19(1):833.

24. Japanese gastric cancer treatment guidelines 2014 (ver. 4). Gastric cancer : official journal of the International Gastric Cancer Association and the Japanese Gastric Cancer Association. 2017;20(1):119.

25. Japanese classification of gastric carcinoma: 3rd English edition. Gastric cancer : official journal of the International Gastric Cancer Association and the Japanese Gastric Cancer Association. 2011;14(2):101-112.

26. Sano T, Coit DG, Kim HH et al. Proposal of a new stage grouping of gastric cancer for TNM classification: International Gastric Cancer Association staging project. Gastric cancer : official journal of the International Gastric Cancer Association and the Japanese Gastric Cancer Association. 2017;20(2):217-225.

27. NCI CTEP. Common Terminology Criteria for Adverse Events (CTCAE) Version 4.0. 2009.

28. Clavien PA, Barkun J, de Oliveira ML et al. The Clavien-Dindo classification of surgical complications: five-year experience. Annals of surgery. 2009;250(2):187-196.

29. Katayama H, Kurokawa Y, Nakamura K et al. Extended Clavien-Dindo classification of surgical complications: Japan Clinical Oncology Group postoperative complications criteria. Surgery today. 
2016;46(6):668-685.

30. Tsujimoto $\mathrm{H}$, Ichikura $\mathrm{T}$, Ono $\mathrm{S}$ et al. Impact of postoperative infection on long-term survival after potentially curative resection for gastric cancer. Annals of surgical oncology. 2009;16(2):311-318.

31. Sierzega M, Kolodziejczyk P, Kulig J. Impact of anastomotic leakage on long-term survival after total gastrectomy for carcinoma of the stomach. The British journal of surgery. 2010;97(7):1035-1042.

32. Yoo HM, Lee HH, Shim JH et al. Negative impact of leakage on survival of patients undergoing curative resection for advanced gastric cancer. J Surg Oncol. 2011;104(7):734-740.

33. Nagasako Y, Satoh S, Isogaki J et al. Impact of anastomotic complications on outcome after laparoscopic gastrectomy for early gastric cancer. The British journal of surgery. 2012;99(6):849-854.

34. Tokunaga $M$, Tanizawa $Y, B a n d o ~ E$ et al. Poor survival rate in patients with postoperative intraabdominal infectious complications following curative gastrectomy for gastric cancer. Annals of surgical oncology. 2013;20(5):1575-1583.

35. Jiang N, Deng JY, Ding XW et al. Effect of complication grade on survival following curative gastrectomy for carcinoma. World journal of gastroenterology. 2014;20(25):8244-8252.

36. Li Z, Bai B, Ji G et al. Relationship between Clavien-Dindo classification and long-term survival outcomes after curative resection for gastric cancer: A propensity score-matched analysis. International journal of surgery (London, England). 2018;60:67-73.

37. Gertsen EC, Goense L, Brenkman HJF et al. Identification of the clinically most relevant postoperative complications after gastrectomy: a population-based cohort study. Gastric cancer : official journal of the International Gastric Cancer Association and the Japanese Gastric Cancer Association. 2019.

38. Papenfuss WA, Kukar M, Oxenberg J. Morbidity and mortality associated with gastrectomy for gastric cancer et al. Morbidity and mortality associated with gastrectomy for gastric cancer. Annals of surgical oncology. 2014;21(9):3008-3014.

39. Wang $S, X u L$, Wang Q et al. Postoperative complications and prognosis after radical gastrectomy for gastric cancer: a systematic review and meta-analysis of observational studies. World J Surg Oncol. 2019;17(1):52.

40. Finnerty CC, Mabvuure NT, Ali A, Kozar RA et al. The surgically induced stress response. JPEN Journal of parenteral and enteral nutrition. 2013;37(5 Suppl):21s-29s.

41. Alazawi W, Pirmadjid N, Lahiri R et al. Inflammatory and Immune Responses to Surgery and Their Clinical Impact. Annals of surgery. 2016;264(1):73-80.

42. McMillan DC. Systemic inflammation, nutritional status and survival in patients with cancer. Current opinion in clinical nutrition and metabolic care. 2009;12(3):223-226.

43. Mantovani A, Allavena P, Sica A et al. Cancer-related inflammation. Nature. 2008;454(7203):436-444.

44. McDonald B, Spicer J, Giannais B et al. Systemic inflammation increases cancer cell adhesion to hepatic sinusoids by neutrophil mediated mechanisms. International journal of cancer. 2009;125(6):1298-1305. 
45. Hsu RY, Chan CH, Spicer JD et al. LPS-induced TLR4 signaling in human colorectal cancer cells increases beta 1 integrin-mediated cell adhesion and liver metastasis. Cancer research. 2011;71(5):1989-1998.

\section{Tables}

TABLE 1. Clinicopathological characteristics of entire cohort.

\begin{tabular}{|ll|}
\hline & No. of patients(1667) \\
\hline Age (years): mean \pm standard deviation & $58.0 \pm 11.3$ \\
\hline Sex ratio (Male/Female) & $1154 / 513$ \\
\hline Preoperative albumin (g/L) : mean \pm standard deviation & $40.46 \pm 4.32$ \\
\hline Comorbidities (Yes/No) & $444 / 1223$ \\
\hline Surgical approach (Open/ Laparoscopic) & $1478 / 189$ \\
\hline Surgical procedure (Distal /Proximal /Total) & $998 / 212 / 457$ \\
\hline Extent of lymphadenectomy (<D2 / $\geq D 2)$ & $49 / 1618$ \\
\hline Resection of other organs (Yes/No) & $67 / 1600$ \\
\hline Perioperative blood transfusion (Yes/No) & $262 / 1405$ \\
\hline Tumor location (Upper/Middle/Lower/Multiple) & $416 / 148 / 955 / 148$ \\
\hline Tumor size (cm) : mean \pm standard deviation & $5.18 \pm 2.84$ \\
\hline Macroscopic type (Bormann 0/1/2/3/4/5) & $316 / 44 / 696 / 518 / 93$ \\
\hline Histological differentiation (G1 + G2/G3 + G4) & $518 / 1149$ \\
\hline Depth of invasion (1/2/3/4) & $348 / 242 / 276 / 801$ \\
\hline Nodal involvement (0/1/2/3) & $525 / 303 / 293 / 546$ \\
\hline Pathological stage (I/II/III) & $402 / 383 / 882$ \\
\hline Adjuvant chemotherapy (Yes/No) & $838 / 829$ \\
\hline
\end{tabular}

TABLE 2. Univariate and multivariable logistic regression analysis of risk factors for POCs 


\begin{tabular}{|c|c|c|c|c|}
\hline & \multicolumn{2}{|c|}{ Univariate analysis } & \multicolumn{2}{|c|}{ Multivariable analysis } \\
\hline & $\mathrm{OR}(95 \% \mathrm{Cl})$ & $\begin{array}{l}P \\
\text { value }\end{array}$ & $\mathrm{OR}(95 \% \mathrm{Cl})$ & $\begin{array}{l}\mathrm{P} \\
\text { value }\end{array}$ \\
\hline Age $(\geq 65$ vs. $<65)$ & $\begin{array}{l}1.70(1.29- \\
2.23)\end{array}$ & $<.001$ & $\begin{array}{l}1.54(1.16- \\
2.04)\end{array}$ & 0.003 \\
\hline Gender (Male vs. female) & $\begin{array}{l}0.84(0.63- \\
1.11)\end{array}$ & 0.220 & & \\
\hline Preoperative albumin ( $\geq 35$ vs. $<35 \mathrm{~g} / \mathrm{L}$ ) & $\begin{array}{l}0.77(0.53- \\
1.14)\end{array}$ & 0.192 & & \\
\hline Comorbidities (Yes vs. No) & $\begin{array}{l}1.70(1.29- \\
2.22)\end{array}$ & $<.001$ & $\begin{array}{l}1.42(1.06- \\
1.91)\end{array}$ & 0.019 \\
\hline $\begin{array}{l}\text { Surgery approach (Laparoscopic vs. } \\
\text { Open) }\end{array}$ & $\begin{array}{l}1.25(0.86- \\
1.84)\end{array}$ & 0.243 & & \\
\hline Gastrectomy (Total vs. Partial) & $\begin{array}{l}1.20(0.91- \\
1.59)\end{array}$ & 0.196 & & \\
\hline Lymphadenectomy ( $\geq$ D2vs.<D2) & $\begin{array}{l}3.24(1.01- \\
10.48)\end{array}$ & 0.038 & $\begin{array}{l}3.80(1.16- \\
12.41)\end{array}$ & 0.027 \\
\hline Resection of other organs (Yes vs. No) & $\begin{array}{l}1.42(0.79- \\
2.56)\end{array}$ & 0.240 & & \\
\hline $\begin{array}{l}\text { Perioperative blood transfusion (Yes vs. } \\
\text { No) }\end{array}$ & $\begin{array}{l}1.69(1.23- \\
2.32)\end{array}$ & 0.001 & $\begin{array}{l}1.43(1.02- \\
2.01)\end{array}$ & 0.040 \\
\hline Tumor size ( $\geq 5$ vs. $<5 \mathrm{~cm})$ & $\begin{array}{l}1.12(0.87- \\
1.45)\end{array}$ & 0.378 & & \\
\hline Tumor location (Multiple vs. U/M/L) & $\begin{array}{l}1.38(0.91- \\
2.09)\end{array}$ & 0.126 & & \\
\hline $\begin{array}{l}\text { Macroscopic type (Bormann 3-4 vs. 0- } \\
\text { 2) }\end{array}$ & $\begin{array}{l}1.07(0.82- \\
1.39)\end{array}$ & 0.633 & & \\
\hline $\begin{array}{l}\text { Histological differentiation (G3/G4 } \\
\text { vs.G1/G2) }\end{array}$ & $\begin{array}{l}0.88(0.67- \\
1.16)\end{array}$ & 0.365 & & \\
\hline Depth of invasion (T4 vs.T1/2/3) & $\begin{array}{l}1.04(0.80- \\
1.34)\end{array}$ & 0.789 & & \\
\hline Nodal involvement (N+vs. N0) & $\begin{array}{l}1.02(0.77- \\
1.34)\end{array}$ & 0.916 & & \\
\hline
\end{tabular}

TABLE 3. Univariate and multivariate COX regression analysis of prognostic factors for OS 


\begin{tabular}{|c|c|c|c|c|c|c|}
\hline & \multicolumn{3}{|c|}{ Univariate analysis } & \multicolumn{2}{|c|}{$\begin{array}{l}\text { Multivariate } \\
\text { analysis* }\end{array}$} & \multirow{2}{*}{$\begin{array}{c}\text { Multivariate } \\
\text { analysis\# }\end{array}$} \\
\hline & $\mathrm{HR}(95 \% \mathrm{Cl})$ & $\begin{array}{l}\mathrm{P} \\
\text { value }\end{array}$ & $\mathrm{HR}(95 \% \mathrm{Cl})$ & $P$ value & $\mathrm{HR}(95 \% \mathrm{Cl})$ & \\
\hline Age $(\geq 65$ vs. $<65)$ & $\begin{array}{l}1.26(1.07- \\
1.49)\end{array}$ & 0.006 & $\begin{array}{l}1.13(0.95- \\
1.35)\end{array}$ & 0.164 & $\begin{array}{l}1.14(0.96- \\
1.36)\end{array}$ & 0.131 \\
\hline $\begin{array}{l}\text { Gender (Male vs. } \\
\text { female) }\end{array}$ & $\begin{array}{l}1.02(0.86- \\
1.20)\end{array}$ & 0.835 & & & & \\
\hline $\begin{array}{l}\text { Preoperative } \\
\text { albumin }(\geq 35 \text { vs. } \\
<35 \mathrm{~g} / \mathrm{L})\end{array}$ & $\begin{array}{l}1.04(0.81- \\
1.33)\end{array}$ & 0.782 & & & & \\
\hline $\begin{array}{l}\text { Comorbidities (Yes } \\
\text { vs. No) }\end{array}$ & $\begin{array}{l}1.20(1.01- \\
1.42)\end{array}$ & 0.034 & $\begin{array}{l}1.07(0.89- \\
1.28)\end{array}$ & 0.486 & $\begin{array}{l}1.07(0.90- \\
1.29)\end{array}$ & 0.447 \\
\hline $\begin{array}{l}\text { Surgery approach } \\
\text { (Laparoscopic vs. } \\
\text { Open) }\end{array}$ & $\begin{array}{l}0.68(0.52- \\
0.90)\end{array}$ & 0.006 & $\begin{array}{l}0.83(0.63- \\
1.09)\end{array}$ & 0.179 & $\begin{array}{l}0.84(0.64- \\
1.10)\end{array}$ & 0.204 \\
\hline $\begin{array}{l}\text { Gastrectomy (Total } \\
\text { vs. Partial) }\end{array}$ & $\begin{array}{l}1.67(1.43- \\
1.96)\end{array}$ & $<.001$ & $\begin{array}{l}1.13(0.95- \\
1.34)\end{array}$ & 0.164 & $\begin{array}{l}1.12(0.95- \\
1.33)^{-}\end{array}$ & 0.176 \\
\hline $\begin{array}{l}\text { Lymphadenectomy } \\
\text { ( } \geq \mathrm{D} 2 \mathrm{vs} .<\mathrm{D} 2)\end{array}$ & $\begin{array}{l}0.80(0.53- \\
1.20)\end{array}$ & 0.277 & & & & \\
\hline $\begin{array}{l}\text { Resection of other } \\
\text { organs (Yes vs. No) }\end{array}$ & $\begin{array}{l}1.23(0.85- \\
1.78)\end{array}$ & 0.282 & & & & \\
\hline $\begin{array}{l}\text { Perioperative blood } \\
\text { transfusion (Yes } \\
\text { vs. No) }\end{array}$ & $\begin{array}{l}1.46(1.21- \\
1.77)\end{array}$ & $<.001$ & $\begin{array}{l}1.12(0.91- \\
1.37)\end{array}$ & 0.293 & $\begin{array}{l}1.12(0.91- \\
1.37)\end{array}$ & 0.276 \\
\hline $\begin{array}{l}\text { Tumor size ( } \geq 5 \text { vs. } \\
<5 \mathrm{~cm} \text { ) }\end{array}$ & $\begin{array}{l}2.18(1.85- \\
2.57)\end{array}$ & $<.001$ & $\begin{array}{l}1.30(1.07- \\
1.57)\end{array}$ & 0.007 & $\begin{array}{l}1.28(1.06- \\
1.54)\end{array}$ & 0.011 \\
\hline $\begin{array}{l}\text { Macroscopic type } \\
\text { (Bormann 3-4 vs. } \\
0-2 \text { ) }\end{array}$ & $\begin{array}{l}1.81(1.55- \\
2.10)\end{array}$ & $<001$ & $\begin{array}{l}1.06(0.89- \\
1.26)\end{array}$ & 0.504 & $\begin{array}{l}1.06(0.90- \\
1.26)^{-}\end{array}$ & 0.492 \\
\hline $\begin{array}{l}\text { Histological grade } \\
\text { (G3/G4 vs.G1/G2) }\end{array}$ & $\begin{array}{l}1.43(1.20- \\
1.70)\end{array}$ & $\begin{array}{l}< \\
0.001\end{array}$ & $\begin{array}{l}1.15(0.96- \\
1.38)\end{array}$ & 0.126 & $\begin{array}{l}1.15(0.96- \\
1.38)\end{array}$ & 0.132 \\
\hline $\begin{array}{l}\text { Depth of invasion } \\
\text { (T4 vs.T1/2/3) }\end{array}$ & $\begin{array}{l}3.03(2.57- \\
3.58)\end{array}$ & $<001$ & $\begin{array}{l}2.05(1.70- \\
2.47)\end{array}$ & $<0.001$ & $\begin{array}{l}2.06(1.71- \\
2.49)\end{array}$ & $<0.001$ \\
\hline $\begin{array}{l}\text { Nodal involvement } \\
(\mathrm{N}+\text { vs. N0) }\end{array}$ & $\begin{array}{l}3.31(2.67- \\
4.10)\end{array}$ & $<001$ & $\begin{array}{l}2.42(1.93- \\
3.04)\end{array}$ & $<0.001$ & $\begin{array}{l}2.41(1.92- \\
3.02)\end{array}$ & $<0.001$ \\
\hline $\begin{array}{l}\text { Adjuvant } \\
\text { chemotherapy (Yes } \\
\text { vs. No) }\end{array}$ & $\begin{array}{l}0.92(0.79- \\
1.08)\end{array}$ & 0.300 & $\begin{array}{l}0.77(0.66- \\
0.90)\end{array}$ & 0.001 & $\begin{array}{l}0.78(0.66- \\
0.91)\end{array}$ & 0.002 \\
\hline
\end{tabular}




\begin{tabular}{|c|c|c|c|c|c|c|}
\hline & \multicolumn{3}{|c|}{ Univariate analysis } & \multicolumn{2}{|c|}{$\begin{array}{l}\text { Multivariate } \\
\text { analysis* }\end{array}$} & \multirow{2}{*}{$\begin{array}{l}\text { Multivariate } \\
\text { analysis\# }\end{array}$} \\
\hline POCs (Yes vs. No) & $\begin{array}{l}1.50(1.24- \\
1.81)\end{array}$ & $\begin{array}{l}<.001 \\
0.01\end{array}$ & $\begin{array}{l}1.47(1.22- \\
1.78)\end{array}$ & $<0.001$ & & \\
\hline ICs (Yes vs. No) & $\begin{array}{l}1.39(1.13- \\
1.72)\end{array}$ & 0.002 & & & $\begin{array}{l}1.34(1.08- \\
1.66)\end{array}$ & 0.007 \\
\hline NICs (Yes vs. No) & $\begin{array}{l}1.39(1.01- \\
1.91)\end{array}$ & 0.045 & & & $\begin{array}{l}1.34(0.97- \\
1.86)\end{array}$ & 0.075 \\
\hline
\end{tabular}

* Multivariate analysis describing the prognosis of POCs for gastric cancer patients. \# Multivariate analysis describing the prognosis of ICs and NICs for gastric cancer patients.

TABLE 4.Univariate and multivariate COX regression analysis in terms of specific complication.

\begin{tabular}{|lllll|}
\hline & \multicolumn{3}{l}{ Univariate analysis } & \multicolumn{2}{l|}{ Multivariate analysis } \\
\hline HR(95\%Cl) & P value & $\mathrm{HR}(95 \mathrm{Cl})$ & P value \\
\hline Pulmonary infection & $1.40(1.12-1.77)$ & 0.004 & $1.52(1.20-1.91)$ & $<0.001$ \\
\hline Abdominal abscess & $1.50(0.87-2.60)$ & 0.145 & & \\
\hline Anastomotic leakage & $1.18(0.30-4.74)$ & 0.813 & & \\
\hline Wound infection & $1.27(0.53-3.07)$ & 0.588 & & \\
\hline Cholecystitis & $1.75(0.56-5.43)$ & 0.330 & & \\
\hline Gastroparesis & $1.26(0.76-2.11)$ & 0.373 & & \\
\hline Intestinal obstruction & $0.89(0.44-2.56)$ & 0.894 & & \\
\hline Pleural effusion & $1.35(0.50-3.60)$ & 0.571 & & \\
\hline Intra-abdominal hemorrhage & $0.91(0.29-2.83)$ & 0.911 & & \\
\hline Arrhythmia & $2.50(0.94-6.68)$ & 0.059 & & \\
\hline
\end{tabular}

\section{Figures}




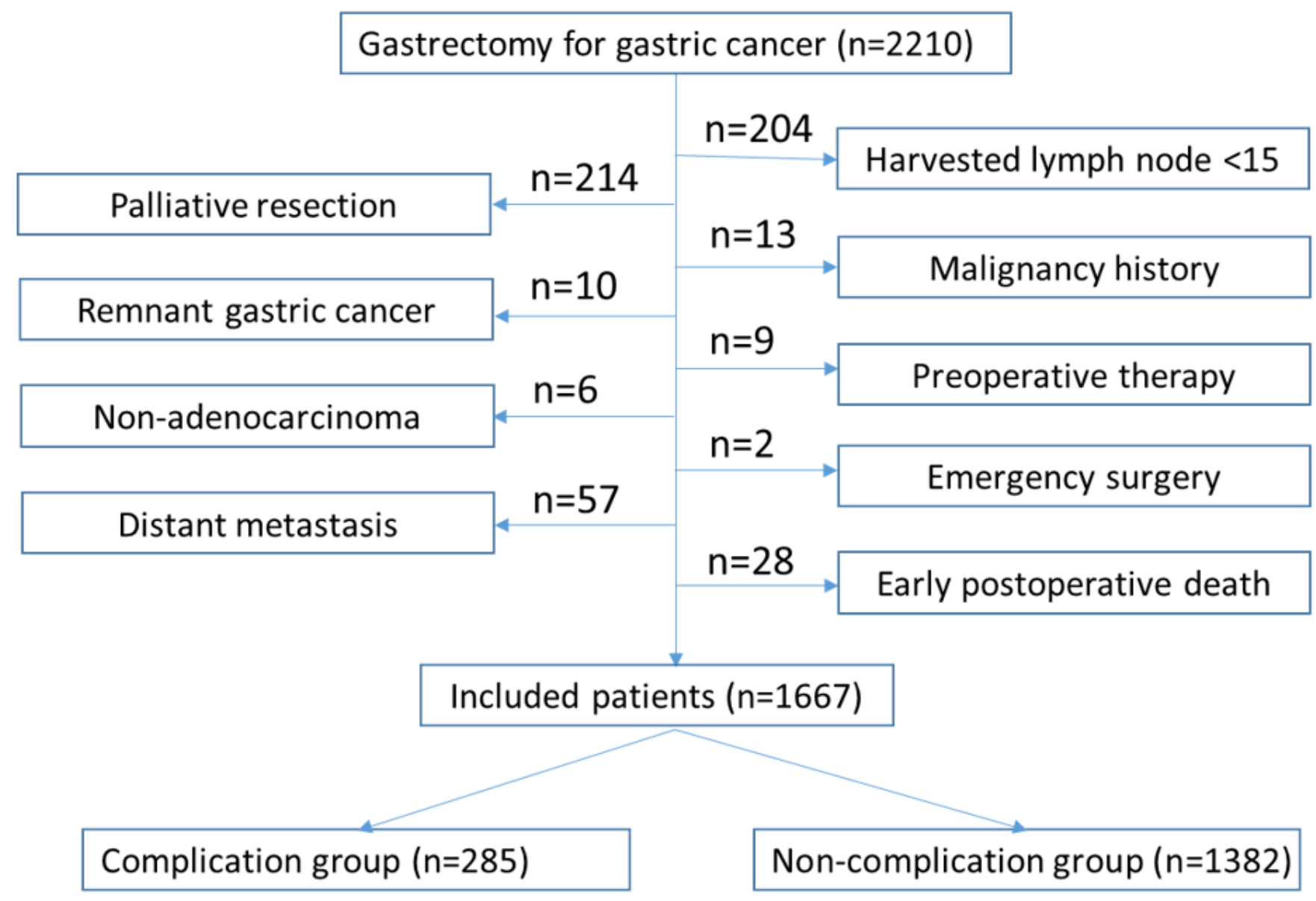

Figure 1

The flow diagram of gastric cancer patients enrolled in this study 

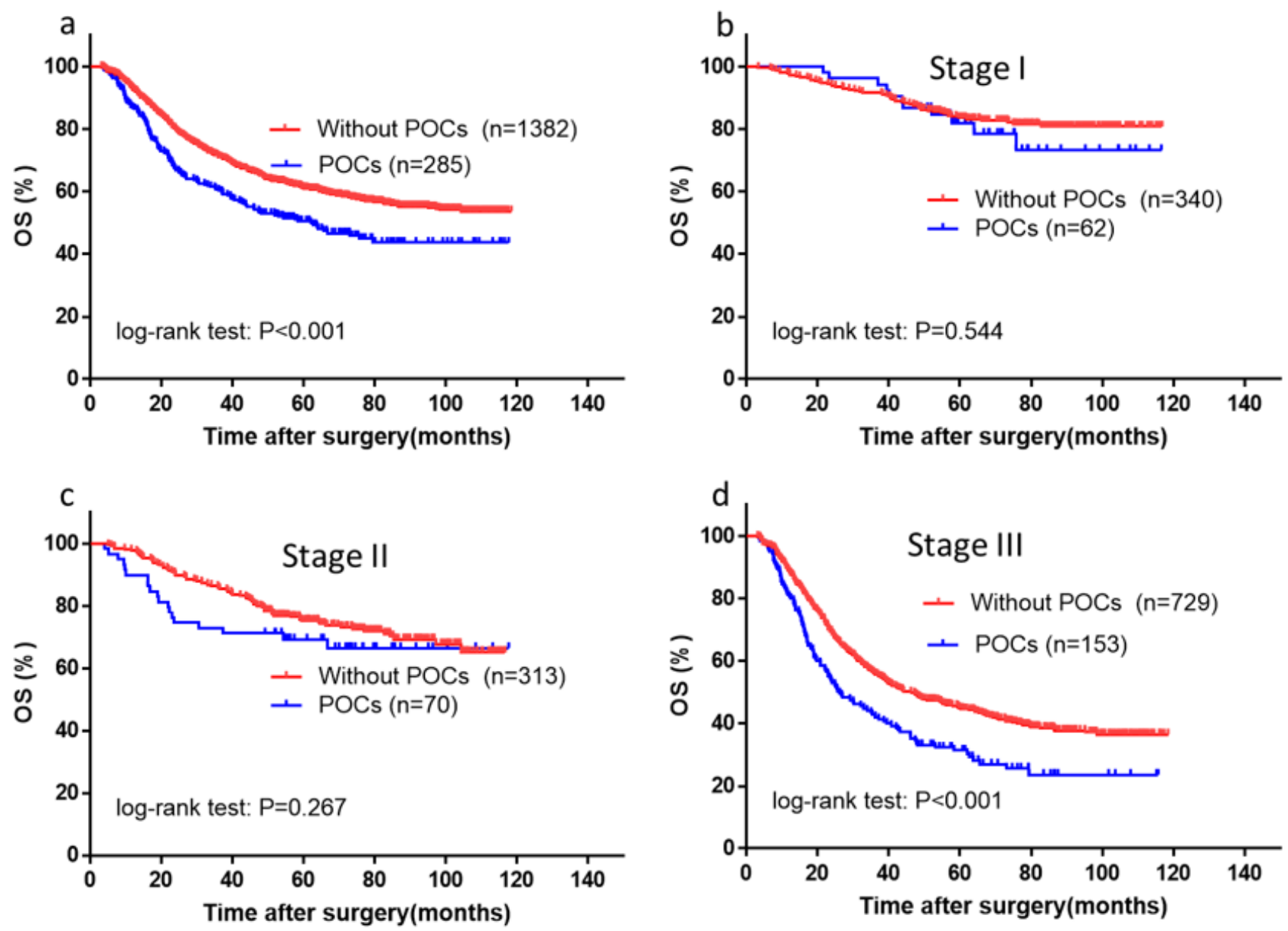

Figure 2

Kaplan-Meier survival analysis of POC in all patients (a) and in Stage I (b), in Stage II (c), and in Stage III (d)) patients. The significance of the difference between survival curves was calculated by the log-rank test. 

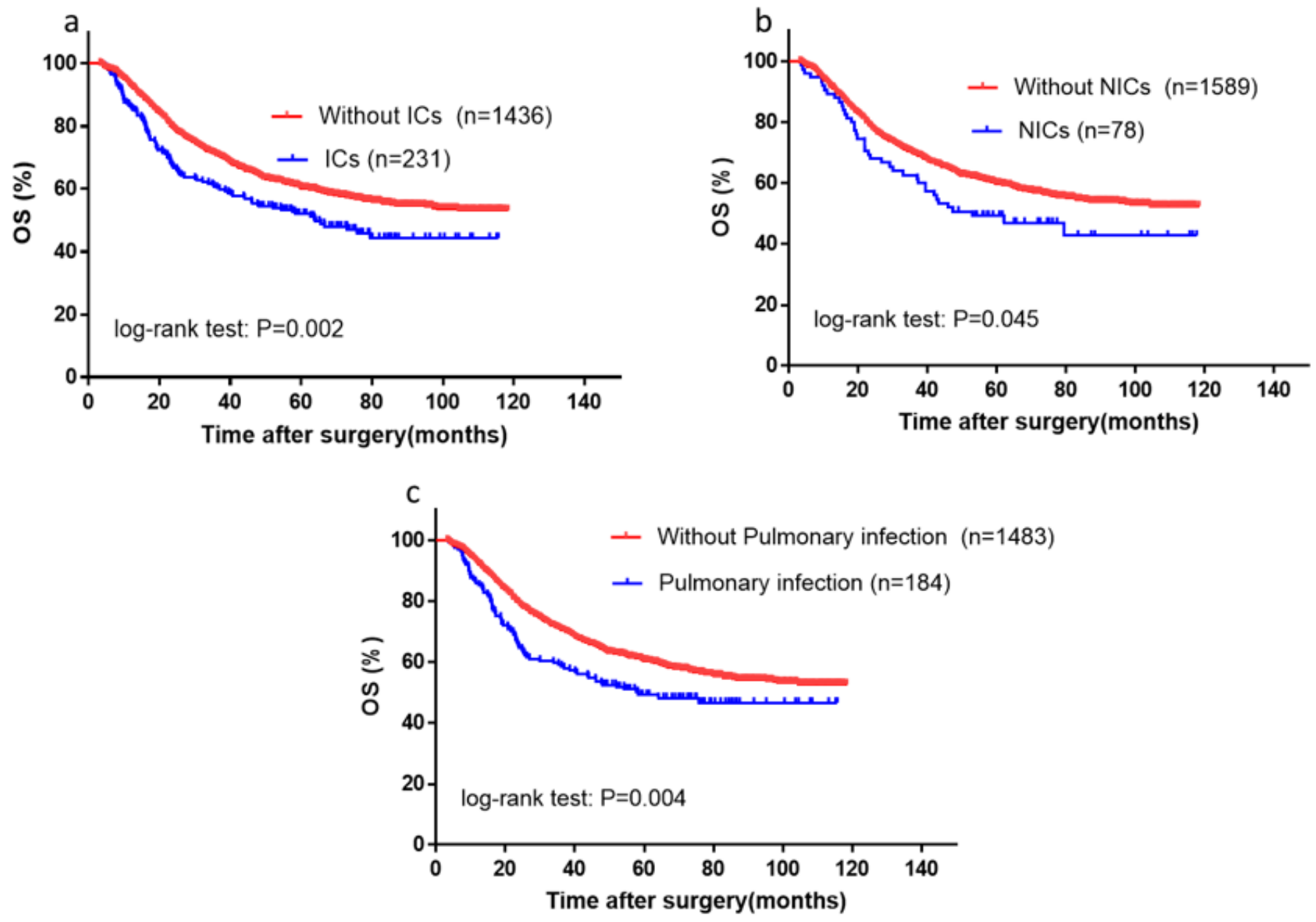

Figure 3

Kaplan-Meier survival analysis according to specific POC in all patients: (a) ICs; (b) NICs, and (c) pulmonary infection. The significance of the difference between survival curves was calculated by the log-rank test.

\section{Supplementary Files}

This is a list of supplementary files associated with this preprint. Click to download.

- TableS1.docx 